\title{
Coal loading comprehensive supervision system based on the Internet
}

\author{
Wang An-yi ${ }^{1,}$ and Zhang Yan-li, b \\ ${ }^{1}$ School ofXi'an University of Science and technology ,Xi'an 710054 China; \\ ${ }^{2}$ School ofXi'an University of Science and technology, Xi'an 710054China; \\ awanganyi@xust.edu.cn, b'zhangyanlilucky@163.com,
}

Keywords: Internet, Coal loading, Comprehensive regulation

\begin{abstract}
At present, thereexists some problems and shortcomings in loading system for coal mine enterprises, such as can not realize comprehensive management, real-time monitoring and remote control. Aiming at the loading system's defect of information "lonely island" ,this paper based on the analysis of coal transportation andsalesystem's all kinds of communication information demand, uses the wireless network (WIFI) and the advantage of RFID technology, and designs a kind of loading coal comprehensive supervision system based on the Internet. This paper introduces the design plan and business process in detail. Through the practical application, the results shows that the loading system has reached the purpose of controlling loading process and centralized control, enhanced the efficiency of loading, transportation and sale.
\end{abstract}

\section{Introduction}

The tache of loading coal is an important link in the coal transportation and sale chain, Thetache of loading coal willorganiccombine with the coal industry production, transportation and sale organically. With thedevelopment of coal industry, the competitionof coal transportation marketis increasing fiercely. However, in theinformationizationdevelopment today, how to utilize the advanced information and network technology, optimize business processes, improveloading efficiency and response to market demand rapidlyis still a universal concern of the coal enterprises.

Therefore, this paper designs a comprehensive management of coal loading system using the wireless network (WIFI)and RFIDtechnology, based on the Internet. This system is for the information of the vehicleadmission, selling coal numeral, emptyvehicle weighing, forklift loading coal, empty tram freight weighing, sales and the release of doorman to overall supervise,statistics, analysis, backto queryand abnormal measurementdata of the early warning. It can shorten the time of the vehicle into and out of the mining area, improve the efficiency of the process for transportation and sale through the fully closed-loop integration management.

\section{Loading Comprehensive Supervision System}

\section{Analysis demand of the loading system}

The existing coal transportation and sales systems do not involve thetache of loading, so the information of transport and sales are disconnected with the truck loading information,the coaled tram driving away the mining area directly that is not carry on a heavy weighing,and then result in a huge economic loss to the enterprise. In addition,in the tache of loading coal, not accurate data support causes the repeated loading / unloading and low efficient of loading, etc.The current main problems existing in the coal transportation and sales system are the following:

1) The gap between coal bunker and heavy truck weighbridges leads to the traffic jam of coal yard and serious influence of the loading efficiency.

2) The forklift truck was not installed with metrical instrument, causing more or less loading, leading to tram detention and serious influence on the loading efficiency.

3) The loading of each tache also needs artificial internal paper to be submitted and related documents to be processed.

4) There is information "lonely island" that can't be comprehensively managed.

5) The forklift truck cannot realize the real-time monitoring and remote controlling. 
Those problemsare widespread in most of the coal enterprise management, in which the information block inthe junctional points of taches also buries hidden troubles to the management.

\section{The design of loading system}

\section{(1)Theimplementation scheme of loading system}

Coal loading system is a hub of informationexchange in the transportation and sales system, and also is a center of data storage and management of the whole system, including data integration, data storage and data distribution.The system development is based on the android platform, uses the B/S mode, and could realize the intelligent identification of the tram and the real-time acquisition, analysis, storage, encryption andrelease of the transportation data. Coal loading system of the concrete implementation plan is shown as the figure below:

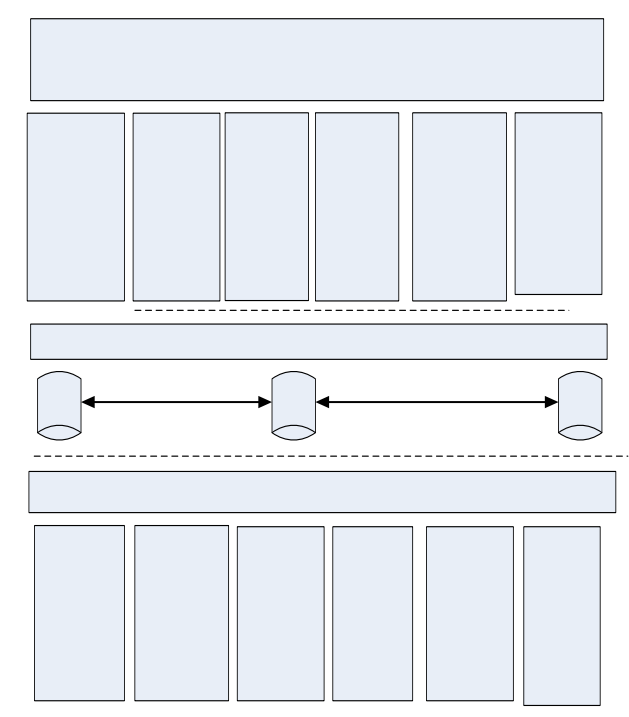

Fig.1.The structure ofloading management platform

Data Integration: data integration module is the data foundation of the system, including the basic information of the tram, coal shed, vehicle traveling data, coal bunker, etc. The basic information of vehicle is from the coal weighbridge system, and includes RFID, electronic tag ID, license plate number, empty weight, load, the type of coal, drivers'driving license number, etc.In the process of driving, when irregularities such as overloading, loading that violates the stipulations and so on occurs, the type of violations and the processing results will be reported to the transportation and sales management platform through the hand-held mobile terminalsoftware.

Data Storage: data were stored in the SQL Server or Oracle database. To ensure the data security, the double machine hot standby and disaster recovery modules are designed. Double machine hot standby module can realize the real-time synchronization on main standby database, and fulfill the standby switch work completely in some exceptional cases, thus ensuring the continuity of the system and the integrity and continuity of the data. Disaster recovery module uses the virtual technology, and it scatters the data to storein different storage devices. The snapshot technology is used for data recovery when the system breakdown.

Data publication: data publication module is based on $\mathrm{B} / \mathrm{S}$ mode. When the mouse moves to the module interface on a coal-carrying vehicle,message box popup automatically, showing the transportation information of vehicles, including the plate number, coal information, destination, etc. If roads are clogging or forbidden,the administrator can send the information to the wireless communication terminal through the transportation and sale information management platform, prompting driversto choose others roads.

(2)The function-introduction of the loading system

The comprehensive management system of the coal mine loadingcan realize the real-time monitoring of transportation, loading, and sales.On the one hand, it is able to monitor the process of distribution, and acquire real-time data, preventing the problems from appearing in the process of 
shipment. On the other hand, when theaccident or problem happens,it can obtain the condition of site at first time, and thencommand, dispatch and control over the events. The functions of loading system are shown in the figure below.

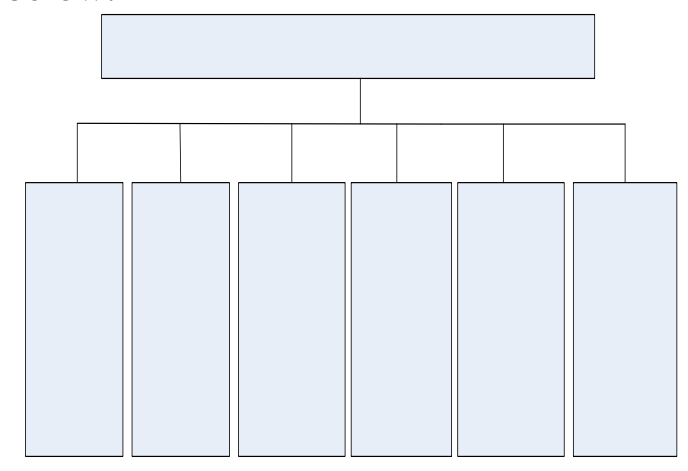

Fig.2.The structure of system function

a) The positioning system of vehicle: The system collects the RFID positioning information of the vehicle, and then sends the collected data to data bank via intranet in the company.The loading system achieves the control for the legitimate coal vehicle of distribution, quantity, runningtrajectory in real-time bycalling the related data from the data bank.It monitors the distribution information and distribution area of the vehicles in each link as transportation, loading,sale in real-time. It also can record the path of coal truck in a mining area, produce the history trace to position and managethe vehicles.

b) Statistical analysis system of the report:It can generate statistics by querying related statements information in the process of production, loading,transport, and sales, such as: the loaders workloadstatistics, forklift driver workload statistics, flight loading statistics (transport, loading,sale), daily report (transport, loading, sale), monthly report (transport, loading, sale).

c) The whole monitoring system: Cameras areinstalled in coal mining area entrances, atthe top of the two ends of the floor scale before and after,and under the coal bunker, to capture the real-time video images and videos, in order to assist the management workers to monitor the gateways in real-time, to assist the weigh man to reasonably control weighing and empty vehicle weighing process, and help the coal workers to control coaling reasonably.

d) Abnormal alarm: When the regulatory link of system (vehicle entry numeral, release, mining area, empty, except for its skin of coal loading (coal shed loading), gross weight, the guard release) data overload, overrun, or abnormal,the exception information will be sent immediately to related workers so that the relevant person could pay attention and make decision in time.

e) Release the information: When situations such as overweight, overrun or abnormal data occurin the regulatory link of the system,the system will immediately spam the information to relevant personnel. The informing way is not only limited to text, but also includes active push function, etc., to prompt relevant personnel to pay attention and make decisions immediately. System can alsodeliver notice about the vehicle distribution of each link (transport, loading, pin), coal loss situation of each link (production, wash and pack, pin), etc.

f) Vehicle management system: It can manage the basic information of the vehicles, including the RFID, electronic tag ID, license plate number, empty weight, load, the type of coal, driver license card number and so on. 


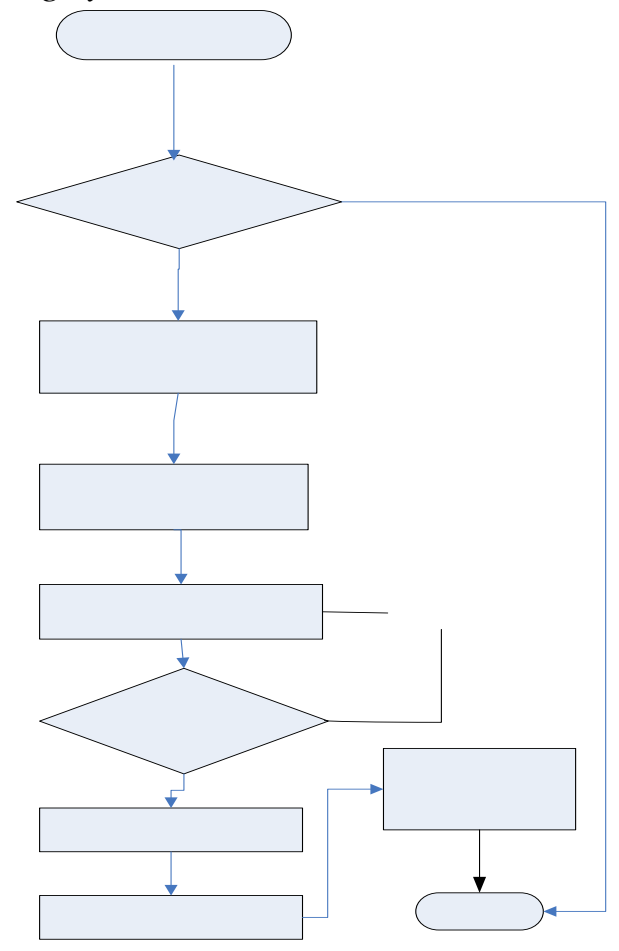

Fig.3.The vehicle management process

Thebusinessprocess of loadingsystem is shown in the figure above, and the implementation steps are as follows.

(1)First of all, judge whether it is the card of the system. If it is, thenmake the coal vehicle queue. If not, the vehicle cannot queue.

(2) The contract coal using radio frequency card, and the coal vehicles are queuing according to the types of coal. Coal mine internal vehicles use the temporary card to unload the coal. While using the temporary card, the vehicles do not have to queue. The operator selects the coal, and then lets the queued vehicles go according to the types of coal.

(3) Empty weighing window weighs the empty transport vehicles. After that the coal will be loaded in the bunker/coal shed; if the bunker/coal shed corresponds with the transport vehicles, the brake will rise for the vehicles to load; otherwise the brake will not rise, and the vehicles need to drive to the right bunker/coal shed to load.

(4)After vehicles load coal in bunker/coal shed, they go to the weighbridge room for weighing. After the weighing, the monitoring system at gate snaps the over weighedvehicle's license plate for comparison. If the comparison result is normal, the vehicle will be released; if abnormal, the vehicle is banned to release.So far, it is the whole process.

\section{The Advantage Of Loading System Design}

Loading platform is developed based on Web mode and it supports remote monitoring. At the same time, the Internet of technology is applied to the function of coal loading module.It can cover the whole marketing system so that relevant departments can understand marketing information effectively in real-time. The combination ofInternet technology and network technology achieves that people, machines and mobile devices synergy with each other. This not only reduces the error, prevent fraud, but also improves the work efficiency.

\section{The application of Internet technology}

Thesystemachieve effectively docking between the RFID technology and the coal mine information technology platform, perfect fusion of sensor technology and communication technology, monitoringproduction process respectively in the information center. It realizes the 
dialogue and communication between objects and people, and the intelligent management and the goal of high production and efficiency is obtained.

\section{The integration technology of mobile information system}

Through integration technology, different application systems can be integrated seamless with coal mine TD network. Through the implementation and development of access adapter plug applied in mining enterprises, the access of different IT systems is completed. It realizes the seamless docking between real-time database interface of the production management and the relational database interface of information management. And the information system could access the production data freely. The safety, validity and efficiency of the coal loading process are ensured.

\section{Summary}

According to the disadvantages of coal transportation and sale system, the integrated coal loading supervision system is designed based on Internet. Through the application of the system, the relevant personnel are able to query the real-time coal of coal production, sales,and all kinds of daily statistics report, data and other information. It is convenient for leaders to master the situation of sales at any time. It specifies the regulatory process of transport, loading, sale, and plugs loopholes. The perfect fusion of Internet technology and sensor technology makes each link of the coal loading visible,standard and efficient. It greatly improves the economic efficiency of enterprises and effectively avoids the coal loss and waste.

\section{References}

[1] Zhang Feng, Gu We. "Theapplication of networking technology in logistics information in coal mine,” J. The ChinaMining2010 (8).

[2] Yu Zhen, "RFID electronic label based on the networking of logistics management system,” J. Microcomputer Information, 2006 (2)

[3] Cheng Man,Wang Ranghui, “The research and application of networking technology,” J. The world of Geographical Information, 2010 (05).

[4] Zhang Guochen, “Analysis and design of coal transportation system," J. Mechanical Engineering \& Automation, 2010 (03).

[5] Tan Zhanglu, ZhaoDunchao, LvMing, "Study on the marketing of intelligent scheduling system in Coal Enterprises,” J. Coal Engineering, 2013 (07).

[6] Ren Liang, Tang Lin, "Design and implementation of coal transportation system is based on B/S,” J. colliery engineering, 2012, 31 (11).

[7] GuanYongwe, "Solution for coal sales management information system," J. Coal Mine Modernization, 2005, (2):71-73.

[8] ZhuYan, "Study on coal marketing information based on Internet," D. Hefei Industrial University, 2011.

[9] Cheng Peng, Geng Haijiang, “Application of IOT technology in coal mine management," J. Technology Information, 2011, (9):110-111.

[10]Li Weidong,“The application of RFID in logistics information management,” D. University of Electronic Science and Technology, 2012. 